Viso: Cadernos de estética aplicada

Revista eletrônica de estética

ISSN 1981-4062

No 28, jan-jun/2021

http://www.revistaviso.com.br/

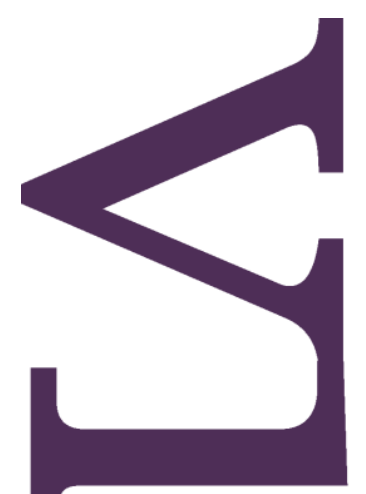

\title{
O sublime e a pintura: entre a sensação no tempo e a destruição da beleza
} Sulamita Fonseca Lino 


\section{RESUMO}

O sublime e a pintura: entre a sensação no tempo e a destruição da beleza

A pintura de Barnett Newman Vir heroïcus sublimis (1950) e seu texto The Sublime is Now (1950) foram referências para o debate sobre o sublime e pintura em autores como Lyotard, Danto e Saint Girons. Além disso, o pintor destaca sua leitura da obra de Burke. Este trabalho pretende analisar, a partir do encontro de todas essas referências, como se deu a aproximação da pintura com o sublime no âmbito da filosofia.

Palavras-chave

sublime; belo; pintura; elevação

\section{ABSTRACT}

Sublime and Painting: Between Time Sensation and Beauty Destruction

Barnett Newman's painting Vir heroïcus sublimis (1950) and his text The Sublime is Now (1950) were references to a debate about sublime and painting in authors such Lyotard, Danto e Saint Girons. In addition, the painter writes show evidences that he was a Burke reader. This work considered those references for analyses the approach of painting and sublime in philosophy subject.

Keywords

sublime; beauty; painting; elevation 
FONSECA LINO, Sulamita. "O sublime e a pintura: entre a sensação no tempo e a destruição da beleza". Viso: Cadernos de estética aplicada, v. 15, $\mathrm{n}^{\circ} 28$ (janjun/2021), p. 53-78.

DOI: 10.22409/1981-4062/v28i/399

Aprovado: 28.06.2021. Publicado: 15.08.2021.

(C) 2021 Sulamita Fonseca Lino. Esse documento é distribuído nos termos da licença Creative Commons Atribuição-NãoComercial 4.0 Internacional (CC-BY-NC), que permite, exceto para fins comerciais, copiar e redistribuir o material em qualquer formato ou meio, bem como remixá-lo, transformá-lo ou criar a partir dele, desde que seja dado o devido crédito e indicada a licença sob a qual ele foi originalmente publicado.

Licença: http://creativecommons.org/licenses/by-nc/4.0/deed.pt_BR

Accepted: 28.06.2021. Published: 15.08.2021.

(C) 2021 Sulamita Fonseca Lino. This document is distributed under the terms of a Creative Commons Attribution-NonCommercial 4.0 International license (CC-BY-NC) which allows, except for commercial purposes, to copy and redistribute the material in any medium or format and to remix, transform, and build upon the material, provided the original work is properly cited and states its license.

License: $\underline{\text { http://creativecommons.org/licenses/by-nc/4.0/ }}$ 
Em 1948, foi publicado o texto The Sublime Is Now, ${ }^{1}$ do pintor norte-americano Barnett Newman. Em 1950, ele pintou uma tela de grades dimensões $(2,40 \mathrm{~m} \times 5,40 \mathrm{~m})$ chamada Vir heroïcus sublimis, uma obra abstrata, cuja composição foi elaborada através de superfícies de cores quentes [colorfields] e linhas verticais contínuas [zips], que, na definição de seus contemporâneos, marca a autonomia, o valor expressivo e espacial da cor. $^{2}$ Essa conjuntura faz emergir um problema complexo, tendo em vista que seu trabalho foi referência para reflexões filosóficas sobre o sublime na contemporaneidade, como nos textos de Lyotard, Sublime à présent (1985), 0 instante, Newman (1997) ${ }^{3}$, de Saint Girons (1993, 2005, 2009), e no Abuso da beleza (2015), de Danto. Em contrapartida, Newman estabeleceu vínculos com a filosofia e, a partir deles, duas questões se destacam: o fato de ele ter sido leitor do $A$ Philosophical Enquiry into the Origin of our Ideas of the Sublime and the Beautiful (1757) de Burke, e a maneira como organiza seus textos, definida por Lyotard (1997) como "monólogos", uma vez que o artista não faz referência direta a nenhum outro lógos. Por isso, na produção teórica do pintor, junto à questão do sublime encontramos o tema de oposição ao belo, no caso, seu argumento de que houve um esforço da arte moderna para destruir a beleza, aspecto esse que foi analisado por Danto (2015). Este trabalho pretende analisar, a partir do encontro de todas essas referências, como se deu a aproximação da pintura com o sublime no âmbito da filosofia.

\section{A pintura como sensação no tempo}

Lyotard $^{4}$ aborda o sublime da pintura considerando duas referências: uma observação de Boileau encontrada nos prefácios $(1674,1683$ e 1701) de sua tradução do tratado de Longino, e uma passagem de Klee. No primeiro caso, a categoria estética do sublime não está relacionada com algo que possa ser provado ou demonstrado, e sim com aquilo que proporciona sentimento $e$, por isso, ele não pode ser determinado por regras. Já para Klee a arte não imita a natureza, ela "torna visível" um mundo à parte, um 
Zwischenwelt (mundo intermediário), um Nebenwelt (mundo paralelo). Ao trazer isso para a contemporaneidade, Lyotard afirma que as imperfeições, as distorções do gosto e a feiura provocam o efeito do choque, e que esse atributo da pintura moderna, evidenciado pelo pintor suíço, permite a manifestação do informe e do monstruoso, que pode vir a ser sublime. $^{5}$

Em síntese, Lyotard aproxima a pintura do sublime em tempos distintos. Ele reconhece, ainda no século XVIII, na passagem de Boileau, o fato de que o sublime não pode ser constituído a partir de regras, sendo esse argumento fundamental para a produção artística de Klee, no século XX. Nesse sentido, a análise sobre o sublime e a pintura ocorre a partir das seguintes questões: a arte está vinculada ao fazer sentir; o fato de que, nesse processo, ela pode deixar manifestar o feio, o informe e o monstruoso, isso provoca o choque que pode vir a ser sublime; sendo o exemplo do "tornar visível" de Klee uma referência desse processo. Ao traçar uma aproximação entre o sublime e a produção de Klee (texto e pintura), Lyotard aponta para a elaboração teórica de um artista moderno, por isso, faremos uma análise da maneira como Klee lidou com os efeitos da paisagem para observar a possibilidade de pensar a prática artística como uma experiência estética do sublime.

Klee comenta que, no passado, havia a crença na arte como estudo da natureza e que esse trabalho estava relacionado a "uma pesquisa penosamente minuciosa da aparência", na qual - artista e seu objeto procuravam relações "seguindo o caminho físico-ótico através da camada de ar entre nós". ${ }^{6}$ Ele não nega as experiências do passado, pelo contrário, reconhece sua importância: "nesse percurso foram obtidas pinturas notáveis da superfície dos objetos filtrada pelo ar" e foi graças a essa experiência que ocorreu o desenvolvimento da arte da visão ótica. Em síntese, a arte acadêmica ensinou ao artista moderno a observação da natureza. Por outro lado, essa mesma arte não permitia a manifestação das "impressões e representações não-óticas" e "as conquistas da pesquisa da aparência não têm de ser desvalorizadas por causa disso, é 
preciso apenas ampliá-las". ${ }^{7}$ De certa maneira, essa abertura era necessária, porque ele já vivia o momento histórico em que a fotografia estava sendo difundida - daí sua descrição de que o artista:

[...] é mais que uma câmera aperfeiçoada; ele é mais complexo, rico e espacial. É uma criatura sobre a terra e uma criatura dentro do todo, ou seja, uma criatura num astro vagando entre os astros. ${ }^{8}$

[...] [o artista] não atribui a essas formas naturais de manifestação o significado obrigatório que elas têm para os muitos críticos realistas. Ele não estabelece um vínculo tão forte com uma tal realidade, porque não vê nas formas finais a essência do processo da criação natural. Pois, para ele, importam mais as forças formadoras do que as formas finais. ${ }^{9}$

A partir da abordagem sobre a questão da pintura, podemos estudar não só um tema, mas uma experiência da arte. 0 relato de Klee, em seus diários, é fundamental para a análise dessa questão, como, por exemplo, sua experiência diante da paisagem tunisiana, descrita em seu diário em $1914 .{ }^{10}$ Nessa viagem, houve vários fatores que favoreceram a produção de uma nova forma de pensar e representar a paisagem, sendo um ponto de destaque o distanciamento do mundo europeu, que levou o artista a uma mudança com relação à observação do espaço. Em seu diário, ele deixa claro o impacto de sua chegada ao norte da África, onde tudo é distinto, a arquitetura, as cores, os costumes etc., e que, por isso, ele é afetado por novas sensações, que foram representadas em seus desenhos, aquarelas e pinturas. Nesse momento, Klee estabelece uma relação subjetiva com o espaço vivido e afirma que há uma ligação entre a arte, a natureza e o eu; e ele, artista, é o sujeito que deixa as impressões da paisagem provocarem a sua sensibilidade para, a partir dessa experiência, produzir seu trabalho:

A cabeça cheia das impressões da noite anterior. Arte - natureza - eu. Imediatamente pus mãos à obra, pintando aquarelas no bairro árabe. Começa a luta para se chegar a 
uma síntese entre arquitetura urbana e arquitetura pictórica. Ainda não é uma síntese pura, mas é bem bonita; tem muito do espírito da viagem e do entusiasmo que ela provocou, muito do eu. Mais tarde ela será mais objetiva, quando se tiver dissipado um pouco esta deliciosa embriaguez. ${ }^{11}$

Em um primeiro momento, o que interessa a Klee é deixar o registro das formas que o provocaram, para, em seguida, provavelmente em seu ateliê, criar algo mais objetivo. Contudo, mesmo nesses primeiros momentos de embriaguez, ele afirma estar sendo fiel à natureza:

Mas o pequeno terraço na subida do hotel era agradável. Dali pintei uma aquarela reproduzindo uma série de elementos e permanecendo absolutamente fiel à natureza. ${ }^{12}$

Essa fidelidade à natureza passa pelo princípio de deixá-la fazer parte do eu do artista, pois todas as maneiras pelas quais ele descreve o acontecimento da cor e da luz dizem respeito ao fato de o artista ser afetado pelos fenômenos da paisagem. Assim, em um trecho do diário em que ele diz que pintou nos arredores da cidade, primeiramente, ele descreve o lugar: "De manhã bem cedinho, pintei nos arredores da cidade. Luz levemente difusa, suave e clara ao mesmo tempo. Nenhuma névoa". Em seguida, fala sobre o impacto do que observou: "tudo aquilo penetra em mim tão profunda e suavemente; sinto que estou ganhando confiança, e sem fazer esforço". Para, ao final, afirmar que não precisa mais buscar a cor, afinal, ela se manifesta: "a cor me possui. Não preciso ir atrás dela. Ela me possui para sempre, eu sei. É esse o significado dessa hora feliz: a cor e eu somos um. Sou pintor". ${ }^{13}$

A experiência de Klee diz respeito ao vínculo da sua arte com o fazer sentir, apontado por Lyotard ${ }^{14}$, e quando aproximamos sua arte pictórica da narrativa dos seus diários, temos revelada a relação dessa produção com o tempo da vida do artista. Isso tem uma equivalência com uma passagem na qual Lyotard comenta o Prologue for a New Aesthetic (1949) de Newman, onde ele afirma que sua pintura não se detém "à manipulação 
do espaço, nem à imagem, mas sim a uma sensação no tempo". ${ }^{15}$ Foi considerando essa argumentação incompleta que o filósofo francês propôs um estudo sobre o tempo na obra do artista a partir de relatos que abarquem e descrevam acontecimentos da sua vida e que possam proporcionar a elucidação sobre esse tema. Lyotard destaca e procura aproximá-los de sua obra: em 1949, ele visitou os Mounds e as fortificações dos índios Miami em Ohio; em 1963, participou da exposição Recent American Synagogue; em 1966, da exposição Stations of the Cross (Lamma Sabachtan) no Museu Guggenheim. Todos esses fatos foram experiências referenciadas em trabalhos posteriores. Em Newman, reconhecemos dois tipos de narrativa relacionada ao espaço. $\mathrm{A}$ primeira diz respeito à experiência do artista no espaço indígena, as demais ao espaço judaico. Para Lyotard, Newman "condensa" o espaço índio e judaico na tentativa de captar "a presença":

A presença é o instante que interrompe o caos da história e lembra ou chama apenas que 'há' antes de qualquer significado daquilo que há. É uma ideia que podemos qualificar de mística, já que se trata do mistério do ser. Mas o ser não é o significado. Se acreditarmos em Newman, o ser, ao revelar-se no instante, forneceria à 'personalidade' o seu 'significado total'. A expressão é três vezes infeliz. Na ocorrência, nem o significado, nem a totalidade, nem a pessoa estão em jogo. Estas instancias vêm 'depois' de alguma coisa acontecer, para que se habituem a ela. Makom significa lugar, mas esse 'lugar' é também o nome bíblico do Senhor. É necessário entendê-lo como a expressão francesa 'avoir lieu', ou seja: advir. ${ }^{16}$

Saint Girons ${ }^{17}$ corrobora esse argumento e destaca que isso se revela na obra como um todo, ou seja, no título, na pintura e nos argumentos do artista:

Newman faz uso do zip, este risco ou banda de cor vertical que separa sua tela em duas partes ou mais, o espectador é conduzido a subir e descer ao longo desse risco, para promover a proximidade e o distanciamento subsequente de campos coloridos. Ele 
concebeu seu zip a partir do tsimtsoum, o ato de concentração de Deus, que permite a criação dentro da tradição judia. Coloca nos quadros nomes simbólicos: Vir heroïcus sublimis (o homem heroico sublime), As estações da cruz, Ornamento I, Ornamento II.

As aproximações que Lyotard estabeleceu entre as passagens de Klee e Newman, confrontadas com as obras de arte, revelam uma mudança de perspectiva para se pensar a pintura, uma vez que esta passa a estar relacionada não com a imagem, mas com a sensação no tempo. Essa condição aproxima as questões do sublime que Lyotard (1985) reconhece em Boileau: o sublime é aquilo que proporciona sentimento e não está vinculado a regras e, por isso, é tão adequado ao tornar visível de Klee. Em contrapartida, quando optamos por lidar com a produção pictórica de Klee, atrelada aos seus diários, percebemos uma aproximação com o estudo de Lyotard acerca da pintura e a sensação no tempo de Newman. Nesse sentido, o atributo fundamental para a compreensão da pintura moderna, ou do expressionismo abstrato, é não se deter na forma escolhida pelo artista e sim considerar que estamos diante de uma experiência sensível, uma sensação no tempo.

\section{Sublime e pintura no Enquiry}

A pintura, para Burke, está associada aos prazeres provocados pelos "sentimentos sociais", que, por princípio, não podem provocar o sublime, mas sim o belo. Contudo, essa determinação não é rígida, pois, em um outro momento, ela foi aproximada também do sublime. Tendo em vista que, do ponto de vista burkeano, as experiências do belo e do sublime não estão vinculadas, necessariamente, às artes, o tema da pintura foi abordado, de maneira breve, nas partes I, II e IV, nas quais podemos destacar três situações distintas: a pintura e o prazer da imitação, a impossibilidade de a pintura reivindicar o sublime, e um trecho que mais se aproxima de um tratado artístico, no qual ele discute de que maneira a cor pode gerar o sublime. $^{18}$ A partir dessas três situações, Saint Girons ${ }^{19}$ reconhece duas atitudes de Burke na relação entre a pintura e o 
sublime. Em um primeiro momento, ele a nega, por entender que essa arte é estritamente mimética e que, por isso, tem como objetivo a clareza da representação; no limite, tentar pintar o sublime seria cometer o risco do ridículo. Posteriormente, ele muda de opinião, provavelmente, devido ao contato com a coleção de Beaconsfield, de pinturas italianas, francesas e espanholas, e de sua convivência com Joshua Reynolds, cujo texto Discursos sobre arte (1790) reconhece Michelangelo como o "inventor" da arte sublime.

A primeira questão, localizada na parte I, seção XIII, diz respeito à imitação e à natureza do prazer que ela pode proporcionar:

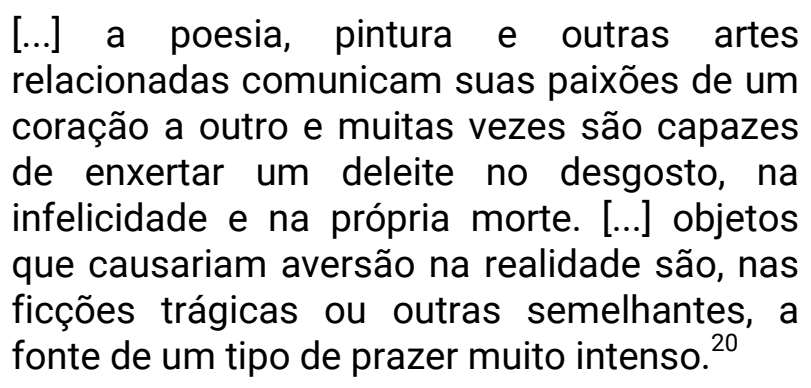

Nesse trecho, percebemos que existe uma defesa do prazer presente nas obras de arte, pois elas são capazes de "promover" um deleite, consequentemente, fica clara a separação entre realidade e ficção. Na seção XVI, Burke reforça esse ponto de vista e recorre aos argumentos presentes na Poética de Aristóteles, que considera uma obra que "discorre tão longa e profundamente sobre a força da imitação". ${ }^{21}$ Ao referenciar a famosa passagem do capítulo IV, ele defende a separação entre o objeto, que não é agradável na realidade, e a sua representação pictórica, que proporciona prazer na imitação: "quando o objeto representado na poesia e na pintura não suscita nenhum desejo de vê-lo na realidade, posso ter certeza de que seu poder na poesia ou na pintura deve-se à imitação, e não a outra coisa que esteja atuando pela coisa em si”. ${ }^{22}$ Ele reafirma a posição de Aristóteles e, a partir dela, procura analisar um tema específico da pintura: a natureza morta. Enquanto o filósofo grego se dedica ao tema dos animais desonrados e cadáveres, Burke prefere falar dos procedimentos da imitação de uma cena banal, defendendo 
que objetos e situações ordinárias podem provocam prazer tanto na condição de objetos imitados quanto na realidade:

Assim ocorre com a maioria das obras que os pintores chamam natureza-morta. Nestas, uma cabana, uma esterqueira, os utensílios mais comuns da cozinha nos causam prazer. Mas quando o objeto da pintura faria com que corrêssemos para vê-lo, se fosse real, por mais estranho que seja o tipo de sentimento que nos causa, podemos ter certeza de que o poder do poema ou da pintura deve-se antes à natureza da própria coisa do que simplesmente ao efeito da imitação ou à reflexão sobre a habilidade do imitador, por maior que ela seja. ${ }^{23}$

Burke, aqui, diferentemente de Aristóteles, faz uma dupla afirmação do prazer, uma vez que, no gênero da natureza morta, ele ocorre a partir da obra e do objeto. Ele anuncia uma adesão às questões da imitação presentes na Poética, mas não as consolida, pois o exemplo escolhido é duplamente agradável, na realidade e na cópia, ao passo que Aristóteles reforça que aquilo que é desagradável na realidade pode provocar prazer na pintura.

A segunda questão, localizada na parte II, é sobre a impossibilidade de a pintura reivindicar o sublime. Esse fato se dá graças à maneira pela qual as "ideias imaginárias e terríveis" são representadas e, consequentemente, pelos sentimentos que elas provocam. Antes de analisarmos a pintura, recorramos ao exemplo da poesia, uma vez que essa arte pode provocar o sublime:

[...] quanto às palavras, elas me parecem afetar-nos de uma maneira muito diferente do que o fazem os objetos naturais ou a pintura e a arquitetura; contudo, as palavras são tão capazes de incitar as ideias de beleza e do sublime quanto aqueles objetos e às vezes um poder muito maior do que qualquer um deles. ${ }^{24}$

$\mathrm{Na}$ pintura, quando ocorre a tentativa de representar "ideias imaginárias e terríveis", corre-se o risco de se apresentar de modo ridículo. Isso acontece porque, apesar de a pintura ser 
uma arte admirada, ela não seria capaz de provocar o mesmo entusiasmo capaz de ser despertado pela poesia e pela retórica:

Quando os pintores tentaram nos apresentar figuras bem definidas dessas ideias exatamente imaginárias e terríveis, na minha opinião foram, na maioria das vezes, malsucedidos; tanto que nunca pude me decidir, com relação a todos os quadros que vi sobre o inferno, se o pintor tinha ou não uma intenção cômica. Muitos pintores lidaram com um assunto desse tipo mediante a reunião do maior número de espectros horrendos que sua imaginação podia inspirar, mas todos os desenhos das tentações de Santo Antônio que tive oportunidade de ver parecem-me antes concepções grotescas e absurdas do que algo capaz de provocar uma paixão verdadeira. ${ }^{25}$

Em contrapartida, quando espectros, quimeras, harpias e figuras alegóricas são narradas na poesia, são grandiosos e impressionantes. Esses efeitos ocorrem porque na poesia as imagens permanecem obscuras e, por isso, são magnificas. Já na pintura, os mesmos temas apareceriam de forma bem definida e poderiam tornar-se ridículos. ${ }^{26}$ Assim, para Burke a representação clara do horrendo, que ocorre nas artes pictóricas, desloca a experiência para o limite do cômico e do ridículo, isso porque a clareza é o oposto do obscuro, e este, por sua vez, é fundamental para a ocorrência do terror. Contudo, no que tange à relação entre a pintura e o sublime, temos em Burke um impasse pois, para que ocorra o sublime, faz-se necessária a experiência do terror e essa, por sua vez, ocorre através do obscuro. Em linhas gerais, a pintura com cenas bem delimitadas (claras) jamais deixaria com que ele ocorresse.

A terceira questão, tratada na parte II, seção XVI, considera os efeitos da cor na pintura, provocados a partir das representações da paisagem, da montanha, do céu noturno. A indicação da paleta de cores deve ocorrer, caso a obra tenha como objetivo despertar a sublimidade: 
Dentre as cores, as suaves e alegres (exceto talvez o vermelho forte, que é jovial) são impróprias para produzir imagens majestosas. Uma montanha imensa coberta de uma reluzente turfa verde nada é, sob esse aspecto, em contraposição a uma outra, escura e sombria; o céu nublado é mais imponente do que o azul; e a noite, mas sublime e solene do que o dia. ${ }^{27}$

Na relação direta de Burke com a pintura, podemos reconhecer quatro tipos de temas, que, de certa maneira, provocam sensações diversas: a pintura do ordinário, que provoca a experiência do agradável; a pintura claramente grotesca, que não provoca o terror, e sim o ridículo e cômico; o gênero histórico, que não desperta um bom efeito; e a paisagem da montanha e do céu que, se for nublada e com azul imponente, leva ao sublime. Em síntese, os efeitos do sublime só seriam provocados pelos estudos de cor nos quais há uma predileção pelos tons escuros, tristes e profundos.

Contudo, mesmo que de maneira incipiente, no final do trecho Burke admite a possibilidade de a pintura provocar o sublime. Saint Girons (2009) atribuiu essa mudança de atitude à sua convivência com Joshua Reynolds, uma vez que, por intermédio dele, Burke teve acesso não só às suas ideias sobre pintura, mas também a coleções privadas de arte. No seu texto Seven Discourses on Art (1769), Reynolds compartilhava da teoria romântica, que, por seu turno, faz distinção entre duas grandes correntes artísticas, polarizadas entre a arte de Rafael e a de Michelangelo. 0 primeiro tem mais gosto e diversão, sua imaginação não é "elevada", sua obra tem composição e desenho corretos, pureza do gosto, uma hábil acomodação da concepção do homem, e tudo isso está vinculado à beleza. 0 segundo tem mais gênio, imaginação, energia e inspiração poética para "ideias vastas e sublimes". Michelangelo é um pintor do sublime, é possível reconhecer em sua obra uma analogia com as ideias presentes no tratado de Longino:

[...] de acordo com Longino, o sublime é a mais elevada excelência que a composição humana pode atingir, compensa a falta de qualquer outra beleza, e expia todas as outras 
deficiências, então Michelangelo exige a preferência. $^{28}$

Reynolds desloca a elevação atribuída ao discurso retórico para a arte, uma vez que ela compensaria "a falta da beleza" e reconciliaria todas as deficiências. Portanto, a elevação não estaria apenas no discurso, ela existiria na pintura, e a arte de Michelangelo é um exemplo disso. O comentário de Saint Girons (2009) contribui para a análise desse trecho de Burke, uma vez que existiu a possível influência de Reynolds. Nesse sentido, o filosofo considera que é fundamental que o artista considere os efeitos da cor para que a pintura possa propiciar a experiência do sublime, algo atrelado à materialidade da pintura, enquanto para Reynolds isso poderia ocorrer através da elevação.

\section{Newman leitor do Enquiry}

No texto The Sublime Is Now, Newman apresentou brevemente sua leitura da filosofia do sublime, iniciando em Longino, passando por Burke, Kant e Hegel. ${ }^{29}$ Contudo, devido à natureza ensaística, ele não aborda sistematicamente nenhum desses autores, detendo-se em suas impressões sobre a relação entre o belo e o sublime. Segundo o pintor, em Longino: "apesar de seu conhecimento da arte não-grega, não poderia livrar-se de suas atitudes platônicas sobre a beleza e do problema do valor, de modo que, para ele, o sentimento de exaltação se tornou sinônimo de perfeita enunciação - uma retórica objetiva"; em Kant, essa confusão se estabelece por meio de "sua teoria da percepção transcendente, na qual o fenômeno é mais que o fenômeno"; em Hegel, há a proposta de uma teoria da beleza "na qual o sublime está na base de uma estrutura de tipos de beleza, criando, assim, uma série de hierarquias em um conjunto de relações com a realidade que é completamente formal". O destaque de Burke ocorre porque nele existe a separação entre o sublime e belo:

Apenas Edmund Burke insistiu em uma separação. Mesmo que seja primitivo e pouco sofisticado, ele é claro e seria interessante saber $o$ quanto os surrealistas foram 
influenciados por ele. Para mim, Burke parece um manual surrealista. ${ }^{30}$

Lyotard $^{31}$ se dedica a explorar a ligação apontada pelo pintor estadunidense entre Burke e o surrealismo e busca uma definição do termo que seja capaz de abarcar a experiência da pintura e o sublime, uma vez que nela observam-se os limites do espaço figurativo e o acontecimento é o próprio objeto pictórico. Segundo o filósofo, a pintura, para Burke, não é capaz de proporcionar o sublime, sendo essa insuficiência provocada por sua permanência nos "constrangimentos da representação figurativa". Em contrapartida, a pintura surrealista, mesmo fazendo uso da figuração, tentou ultrapassar essa insuficiência através da reunião paradoxal de elementos, tendo em vista que ela junta "restos" que têm suas origens na "realidade perceptiva". É uma arte que, na sua essência, está obstinada a "representar e dar a conhecer". ${ }^{32}$

Contudo, o que Lyotard não considerou foi o fato de que Newman, antes de escrever seu "monólogo" sobre o sublime, dedicou-se a outro texto especificamente sobre o surrealismo, Surrealism and the War. ${ }^{33}$ Nele, encontramos a ligação entre a arte surrealista e os horrores da guerra. Segundo o artista, se a humanidade tivesse considerado as imagens produzidas por essa vanguarda, "a guerra nunca teria ocorrido". Ele compara as imagens das atrocidades germânicas com as obras:

Nenhuma pintura existe com melhor surrealismo do que as fotografias das atrocidades alemãs. As pilhas de crânios são a realidade das visões de Tchelitchew. A pilhas de ossos são a realidade das composições de Picasso, da sua escultura. Os corpos monstruosos são os demônios de Ernst. A arquitetura destruída, as ruínas, os corpos grotescos são a realidade surrealista. 0 sadismo dessas imagens, o horror e o pathos estão ao redor de nós. [...] Aqueles que viram os trabalhos surrealistas como brinquedos exóticos de sofisticados decadentes, destacados da vida, não podem negar o fato de que agora esses objetos são espelhos 'superreal' do mundo que estava por vir, do mundo de hoje. ${ }^{34}$ 
De acordo com Lyotard esses horrores da guerra revelados na pintura surrealista estavam inscritos dentro de uma intenção geral da pintura de "representar e dar a acontecer" o agora. ${ }^{35}$ Sendo a pergunta sobre o "agora" na obra de Newman, que é tributária à estética do sublime de Burke:

Quando ele procura a sublimidade no aqui e agora, Newman rompe com a eloquência da arte romântica, mas ele não rejeita sua tarefa fundamental que é a expressão pictural ou outra que seja a testemunha do inexprimível. 0 inexprimível não reside num além, num outro mundo, num outro tempo, mas nisto: que ocorra alguma coisa. Dentro da determinação da arte pictural, o indeterminado, o que Ocorre é a cor, o quadro. A cor, o quadro, enquanto ocorrência, acontecimento, não é exprimível, e é isto que terá de testemunhar. ${ }^{36}$

Existe uma separação entre a abordagem de Lyotard (1985, 1997) sobre as formas pelas quais Newman encarou o sublime burkeano e a maneira como o artista lidou com esse tema. Para Newman, somente Burke insistiu na separação entre o belo e o sublime e seu pensamento "parece um manual surrealista" sem colocar nenhuma referência complementar. ${ }^{37}$ Por outro lado, quando aborda a arte surrealista, ele se detém na forma pictórica, na representação dos horrores da guerra que está por vir. Lyotard (1997) aproxima o surrealismo à ideia do acontecimento e o descreve como uma arte que promove a reunião paradoxal dos elementos figurativos. Contudo, um aspecto une os dois pensamentos, o fato de o pintor norteamericano estar empenhado em produzir uma arte que pertença à experiência do sublime.

\section{Sublime e destruição da beleza}

No texto The Sublime Is Now, Newman faz referência não apenas ao sublime burkeano, mas também à pintura de Michelangelo (grifo nosso):

Michelangelo sabia que o significado das humanidades gregas para o seu tempo envolvia fazer Cristo - o homem em Cristo - 
que é Deus; que seu problema plástico não era nem o medieval, para fazer uma catedral, nem o grego para fazer um homem como deus, mas para fazer uma catedral do homem. Ao fazêlo, estabeleceu um padrão para a sublimidade que a pintura de seu tempo não podia alcançar. ${ }^{38}$

Esse trecho aponta para a possibilidade de existir efetivamente uma sublimidade na pintura, exemplificada na arte voluptuosa de Michelangelo. Podemos supor que o artista norte-americano esteja se referindo à obra da Capela Sistina, no Vaticano, uma vez que, em seu texto, ele compara as diversas atitudes dos homens diante de deus. Do ponto de vista da forma, Michelangelo manifesta nessa obra uma ruptura com a estabilidade renascentista, não por acaso, seu contraponto, como apontado por Reynolds, é a arte de Rafael. Os desenhos das figuras da Capela Sistina apresentam não só uma alteração da proporção das formas do corpo do Renascimento, mas também as deformações do próprio corpo, proporcionadas pelo movimento físico que o artista desejava representar. Isso ocorreu porque, depois de um longo e primoroso trabalho como escultor, Michelangelo levou para a sua pintura um profundo conhecimento do movimento corporal, o que fez com que ele tivesse condições de desenhar e pintar várias posições do corpo humano. Segundo Newman, o artista italiano estabeleceu um "padrão para a sublimidade" ${ }^{39}$; segundo Reynolds, sua imaginação "é vasta e sublime". ${ }^{40}$

Newman, no seu comentário sobre Burke, destaca o fato de que o filósofo lidou com a separação entre o belo e o sublime. ${ }^{41} \mathrm{Em}$ outro trecho ele adiciona a essa oposição o tema da destruição da beleza. Para ele a pintura europeia guarda em sua essência, até os tempos modernos, uma ligação com a Voluptuous Art iniciada por Michelangelo. E foi graças a ela que, séculos depois, os impressionistas insistiram em produzir "uma superfície de traços feios", como uma forma de destruir a retórica da beleza. Para Newman, "o impulso da arte moderna foi seu desejo de destruir a beleza". ${ }^{42}$ Contudo, os impressionistas descartaram a noção renascentista da beleza sem propor "um substituto adequado para uma mensagem 
sublime". Nesse sentido, ele posiciona o sublime em contraste antagônico com o belo:
A invenção da beleza como um ideal tem sido o bicho-papão da arte e das filosofias estéticas europeias. 0 desejo natural do homem nas artes, de expressar sua relação com o Absoluto, passou a ser confundido e identificado com o absolutismo de criações perfeitas - com o fetiche da qualidade - , de modo que o artista europeu tem sido continuamente envolvido na luta moral entre noções de beleza e o desejo de sublimidade. ${ }^{43}$

Danto comenta essa passagem, considerando que no texto de Newman existe o "descarte da noção renascentista de beleza", e ela não foi substituída pela mensagem do sublime, ou seja, são duas negações, uma noção é recusada e nada é colocado no seu lugar. ${ }^{44}$ Newman, contudo, traça um caminho da experiência da arte que se inicia no Impressionismo e que, potencialmente, levaria à destruição da beleza: no início, os impressionistas "estavam aptos a fazer a transferência de valores”, mas não o fizeram, eles apenas reafirmaram a questão geral da beleza; depois, os cubistas e os dadaístas realizaram uma "transferência de valores com o intuito de criar uma nova visão", usando recortes de jornal no lugar da superfície pictórica dos renascentistas e dos impressionistas; essa atitude exalta uma nova experiência, que não é a do sublime. No âmbito da arte moderna, Picasso pode ter um esforço sublime, mas, no fundo, mantém-se na "natureza da beleza"; enquanto Piet Mondrian, por seu turno, dedica-se a "destruir" a pintura do Renascimento por meio da forma pura, buscando o sublime no absoluto das formas perfeitas. Diante desse panorama, Newman conclui que esses últimos atestaram o fracasso da arte europeia em alcançar o sublime. ${ }^{45}$ Se, por um lado, todas essas experiências tentaram destruir a beleza, por outro lado, elas não criaram "uma imagem do sublime", não romperam com o imaginário de figuras e dos temas do Renascimento. Para Newman, somente os artistas não europeus poderiam produzir a arte dessa ruptura:

Nós estamos reafirmando o desejo natural do homem pelo elevado, em consideração a 
nossa relação com as emoções absolutas. Nós não precisamos dos artefatos obsoletos de uma legenda antiquada. Nós estamos criando imagens cuja realidade é auto evidente e que são esvaziadas dos artefatos e apoios que evocam associações com imagens ultrapassadas, tanto sublimes quanto belas. Nós estamos nos libertando dos impedimentos da memória, da associação, da nostalgia, do mito, ou o que tenha sido instrumentos da pintura europeia ocidental. Em vez de fazer catedrais de Cristo, homem ou 'vida', nós estamos fazendo de nós mesmos, dos nossos próprios sentimentos. A imagem que nós produzimos é auto evidente da revelação, real e concreta, que pode ser compreendida por todos que olhem para ela sem lentes nostálgicas da história. ${ }^{46}$

De certa maneira, esse é o argumento central para defender a constituição do Expressionismo Abstrato. Essa poética foi formada a partir de vários processos que não são colocados em sequência, e sim interrelacionados, entendendo que existiu também uma conjunção de fatores que levaram o artista a provocar esse olhar de fundação de uma arte, como um processo que envolve o estudo da forma e a reflexão filosófica. Diante da crítica de Newman à arte europeia, cabe observar sua visita (tardia) à obra dos mestres, descrita por Danto:

Barnett Newman visita o Louvre pela primeira vez em 1968. [...] [ele] tivera o benefício de ler Clement Greenberg e de ter passado por uma fase surrealista. Assim ele é capaz de dizer a seu guia um tanto condescendente - o crítico francês Pierre Schneider - para ver Battaglia di San Romano, de Uccello, como 'uma pintura moderna plana, e de explicar por que o São Sebastião de Mantegna sangra tanto quanto um pedaço de madeira, apesar de ter sido alvejado por diversas flechas. Ele vê a Balsa da Medusa, de Géricault, como algo 'inclinado para cima', como uma das mesas de Cézanne - 'É o tipo de espaço moderno que você não esperaria como esse tipo de retórica'. E, em geral, Newman é capaz de mostrar aos estetas europeus uma ou duas coisas a respeito de como falar sobre os Velhos Mestres e, inicialmente, sobre como olhar para a sua própria obra, que tantos, mesmos 
entre os contemporâneos de Nova York, achavam intratável. Em Rembrandt, por exemplo, Newman vê 'todo o marrom, com uma faixa de luz descendo no meio - como na minha própria pintura' ${ }^{47}$

Nesse relato, encontramos a ênfase no olhar abstrato de Newman diante das obras do Louvre, como se fosse uma lente com a qual o pintor as sintetiza em uma definição objetiva, um exercício de decomposição da forma. Essa narrativa está mais próxima de estudos sobre percepção e composição das artes gráficas nos quais uma obra, figurativa ou abstrata, é submetida às técnicas para reconhecer seus elementos compositivos, tais como linhas, curvas e cores predominantes que podem ser vistas como manchas. ${ }^{48}$

Danto observa que essa visita ao museu francês ocorreu vinte anos depois que Newman havia realizado a obra Ornement I (1948), que ele considerou uma ruptura não só com sua própria pintura, mas com a pintura de maneira geral:

\begin{abstract}
Em minha opinião, não resta dúvida de que Newman associava essa obra com a imensidão transmitida pela ideia do sublime. De certo modo, em uma realização significativa demais, pelo menos na cabeça dele, para ser pensada como meramente bela, ou para ser considerada apenas bela. Algumas décadas depois, Lyotard escreveu 'na estética do sublime [...] a lógica da vanguarda encontra seu axioma'. E fica claro, pelo modo como Newman polariza os dois conceitos, que ele não via nenhuma possibilidade de encontrar o axioma de sua arte com a estética da beleza. Se devia haver uma estética para Ornement I, nada menos do que o sublime seria suficiente. Como mencionei antes, há muitas outras qualidades estéticas além da beleza. Entretanto, nenhuma delas impõe ao belo o mesmo desafio imposto pelo sublime [...]. ${ }^{49}$
\end{abstract}

Ao constituir essa afirmação, Danto mantem a dicotomia entre o sublime e o belo que encontramos em Burke e Newman. Contudo, a relação entre o sublime e a destruição da beleza, proposta pelo pintor, parece ser um caminho que anuncia 0 
desejo de formação do Expressionismo Abstrato. Para isso, Newman desloca o problema do sublime e a pintura do âmbito filosófico para a própria superfície pictórica. Não por acaso, ele recorre a Michelangelo, o artista que deforma a proporção renascentista para proporcionar a ideia de elevação, e percorre a história da arte moderna através das obras do impressionismo, do cubismo etc. Todos esses fatos, por um lado, deixam obscuro se a destruição da beleza é algo que ocorre junto ao sublime ou separadamente; por outro, nos anunciam que não há distinção entre obra e pensamento, como proposto por Saint Girons:

Quando olhamos para um quadro
percebemos a força intrínseca da obra, um
poder que capta o artista, sentido da pintura
pura, que está em Caravaggio, Rembrandt,
Rothko etc. Essas obras fazem pensar na
técnica, os problemas de concepção. A
pintura nos ensina a pensar no quadro, uma
vez como imagem e para além dela, como um
lugar de luta entre aquilo que se manifesta e
aquilo que é aparentemente manifestado.

\section{Conclusão}

Newman considera que a Voluptuous Art de Michelangelo é a essência da pintura europeia, ou seja, a pintura em si guarda o estatuto da intensidade. Para Reynolds, quando se desloca a ideia de elevação do sublime retórico para o sublime pictórico, isso ocorre como um modo de "compensar a falta de beleza", ao passo que o pintor norte-americano retoma a obra de Michelangelo como "padrão de sublimidade". ${ }^{51} \mathrm{Se}$, de um lado, há a quietude da experiência estética do belo, que ocorre por meio de suas formas perfeitas e suas composições equilibradas, de outro, há a experiência do sublime, promovida através da ideia da elevação e da intensidade:

A beleza se encontrava na defensiva desde pelo menos o século XVIII, quando o conceito do sublime entrou pela primeira vez na consciência do lluminismo por meio da tradução feita por Boileau de um texto sobre o assunto escrito por um retórico um tanto obscuro, tradicionalmente conhecido como 
Longino. E também por meio de Uma investigação filosófica acerca da origem do sublime e do belo, do estadista irlandês Edmund Burke.[...] Era inteiramente correto da parte de Newman associar a ideia de beleza com a de perfeição. A marca do sublime, por contraste, era o êxtase, ou enthusiasmos. Esses termos, ou melhor, seus equivalentes, continuam a desempenhar um papel no vocabulário da apreciação estética. ${ }^{52}$

Nesse contraponto entre as experiências da elevação, intensidade, sublime e belo, segundo Danto, Newman qualificou um novo caminho, o que coloca a história da arte como a luta estética entre "a exaltação a ser encontrada na forma perfeita", por um lado, e "o desejo de destruir a forma, por outro, onde a forma pode ser disforme". Contudo, faz parte dessa trajetória a experiência da intensidade, que está presente na pintura desde Michelangelo, e o impulso pela destruição da beleza, que se manifestou a partir dos impressionistas. ${ }^{53}$ Quando Newman reconhece que os artistas europeus ainda mantinham relações com a superfície do Renascimento, ao invés de afirmar a intensidade do sublime, ele reafirma a condição da beleza. Isso remete a uma dialética: a pintura a partir da modernidade teria, simultaneamente, a intensidade e a vontade de destruir a beleza e, ao mesmo tempo, mantém o pacto (renascentista) com ela. Em sua defesa do sublime na pintura, afirma que esse pacto tem de ser rompido de maneira radical através de um novo olhar, que só estaria fora da Europa. Newman reforça a defesa pela pintura do sublime, mas parece ser possível afirmar que seu compromisso é com a "destruição da beleza". ${ }^{54}$ Quando ele vê a pintura dos mestres no Louvre como manchas e composições, ele não está apenas afirmando que seu olhar sobre o mundo é abstrato, mas está reconhecendo ali o pacto desses artistas com manifestações da beleza. Nesse caminho, Newman afirma, mais uma vez, a opção que está no Enquiry de Burke. De um lado, o belo, de outro, o sublime; mas também mantém vínculos com a ideia de elevação presente em Longino.

Ao analisarmos o percurso do pensamento de Newman para estabelecer o sublime na pintura, nos deparamos como os 
seguintes temas: a impossibilidade de a arte europeia romper com a beleza, o fato de Michelangelo ter estabelecido um padrão de sublimidade etc. Contudo, todas essas afirmações podem ser atravessadas pelo argumento da pintura como sensação no tempo, tendo em vista que Newman afirma que os europeus não poderiam produzir uma obra que rompesse verdadeiramente com a nostalgia, mas, cronologicamente, ele afirma isso em um texto escrito vinte anos antes de visitar o Louvre. Nesse sentido, aos termos acesso à descrição do artista diante dos mestres, estamos recorrendo não aos elementos da sua biografia, mas ao material que constitui a sua obra, que nos remete ao tornar visível, proposto por Klee e destacado por Lyotard. A questão sobre o sublime e a pintura está inscrita entre a sensação no tempo e a destruição da beleza, entre lógos e superfície pictórica.

\section{Referências}

BURKE, Edmund. Uma investigação filosófica sobre a origem de nossas idéias do sublime e do belo. Tradução de Enid Abreu. Campinas: Editora Unicamp, 2013.

Recherche philosophique sur l'origine de nos idées $d u$ sublime e du beau. Présentation et traduction de Baldine Saint Girons. Paris: Vrin, 2014.

DANTO, Artur C. O abuso da beleza. Tradução de Pedro Süssekind. São Paulo: Martins Fontes, 2015.

KLEE, Paul. Sobre arte moderna e outros ensaios. Tradução de Pedro Süssekind. Rio de Janeiro: Jorge Zahar, 2001.

Diários. Tradução de João Azenha Jr. São Paulo: Martins Fontes, 1990.

LYOTARD, J.F. "Le sublime, à présent". Po\&sie, n.34 ( $3^{\circ}$ trim., 1985).

O Inumano: considerações sobre o tempo. Lisboa: Estampa, 1997. 
MÈREDIEU, Florence de. Histoire matérielle \& imamatérielle de l'art moderne \& contemporain. Paris: Larousse, 2017.

NEWMAN, Barnnet. Selected Writings and Interviews. Editção organizada por Jonh P. O'Neill. Los Angeles: University of California Press, 1992.

REYNOLDS, Joshua. Seven Discourses on Art. Project Gutenberg, 2005. Disponível em: < https://www.gutenberg.org/files/2176/2176-h/2176-h.htm>. Acesso em 10/07/2020.

SAINT GIRONS, Baldine. Fiat lux: une philosophie du Sublime. Paris: Quai Voltaire, 1993. Le pouvoir esthétique. Paris: Éditions Manicius, 2009.

Le sublime: de l'Antiquité à nos jours. Paris: Desjonquères, 2005

"Présentation". In: BURKE, Edmund. Recherche philosophique sur l'origine de nos idées du sublime e du beau. Paris: Vrin, 2014.

Sulamita Fonseca Lino é professora do Departamento de Arquitetura e Urbanismo da UFOP.

${ }^{1}$ Publicado originalmente na revista The Tiger's Eye, dedicada à literatura e às artes, em uma edição que tematizou seis opiniões a respeito da questão: o que é sublime na arte? (DANTO, 2015).

${ }^{2}$ MÈREDIEU, 2017, p. 110.

${ }^{3}$ Utilizamos aqui a versão em francês (1985) e a tradução para o português (1997) do texto Sublime à présent, e de 0 instante, Newman, por sua vez, apenas a versão em português (1997).

${ }^{4}$ LYOTARD, 1985, p. 102.

${ }^{5}$ LYOTARD, 1985, p. 102.

${ }^{6}$ KLEE, 2001, p. 81.

${ }^{7}$ KLEE, 2011, p. 81.

${ }^{8}$ KLEE, 2001, p. 82.

${ }^{9}$ KLEE, 2002, p. 64. 
${ }^{10}$ Estes trechos foram escritos na formação do artista e por isso são um importante contraponto aos seus escritos posteriores sobre arte, que são da década de 1920.

${ }^{11}$ KLEE, 1991, p. 322.

${ }^{12}$ KLEE, 1991, p. 327.

${ }^{13}$ KLEE, 1991, p. 332.

${ }^{14}$ LYOTARD, 1985.

${ }^{15}$ NEWMAN, 1992.

${ }^{16}$ LYOTARD, 1997, p. 93.

${ }^{17}$ SAINT GIRONS, 2005, p. 152.

${ }^{18}$ Saint Girons (2009, p. 37) destaca que esse trecho influenciou pintores, escultores, paisagistas e arquitetos por confrontar o sublime e o gigantesco, a grandiosidade artificial ou, ainda, a grandeza física e a grandeza estética. Seus princípios da arquitetura, por exemplo, foram de grandes consequências para Boullée e Ledoux, cujos projetos expressam a grandiosidade da forma e a não-ornamentação. Suas reflexões colocaram o sublime próximo das ilusões de ótica por intermédio do jogo da profundidade com a cor e as sombras.

${ }^{19}$ SAINT GIRONS, 2009, p. 37.

${ }^{20}$ BURKE, 2013, p. 63.

${ }^{21}$ BURKE, 2013, p. 70.

${ }^{22}$ BURKE, 2013, p. 70.

${ }^{23}$ BURKE, 2013, p. 70.

${ }^{24}$ BURKE, 2013, p. 199.

${ }^{25}$ BURKE, 2013, p. 88.

${ }^{26}$ BURKE, 2013, p. 88.

${ }^{27}$ BURKE, 2013, p. 107-108.

28 REYNOLDS, 2005. A transcrição desse texto está disponível no site www.gutemberg.net, sendo que nele não há identificação das páginas do original.

${ }^{29}$ NEWMAN, 1992, p. 171.

${ }^{30}$ NEWMAN, 1992, p. 171.

${ }^{31}$ LYOTARD, 1997.

${ }^{32}$ LYOTARD, 1997, p. 91.

${ }^{33}$ Esse texto foi escrito em resposta à divulgação do trabalho dos artistas surrealistas em Nova York, apoiado pela galeria de Peggy Guggenheim, com a exposição, em 1942, organizada por André Breton, The first papers of surrealism. Esse texto é uma provocação aos esforços de André Breton em atacar Ashile Gorky devido às suas fotos dos campos de concentração nazista, realizadas no momento da chegada das tropas das nações aliadas. 
Todos os textos de Newman utilizados neste trabalho tem como referência a edição de seus escritos e entrevistas organizados por O'Neill (1992).

${ }^{34}$ NEWMAN, 1992, p. 95-96.

${ }^{35}$ LYOTARD, 1997, p. 100.

${ }^{36}$ LYOTARD, 1997, p. 99.

${ }^{37}$ NEWMAN, 1992, p. 171.

${ }^{38}$ NEWMAN, 1992, p. 172.

${ }^{39}$ NEWMAN, 1992, p. 172.

${ }^{40}$ REYNOLDS, 2005.

${ }^{41}$ NEWMAN, 1992, p. 172.

${ }^{42}$ NEWMAN, 1992, p. 172.

${ }^{43}$ NEWMAN apud DANTO, 2015, p. 169.

${ }^{44}$ DANTO, 2015, p. 169.

${ }^{45}$ NEWMAN, 1992, p. 172.

${ }^{46}$ NEWMAN, 1992, p. 173.

47 DANTO, 2015, p. 171.

48 Essa teoria da percepção visual tem como uma de suas principais referências a obra de Rudolf Arnheim, Arte e percepção visual: uma psicologia da visão criadora, publicado originalmente em 1954.

${ }^{49}$ DANTO, 2015, p. 186-169.

${ }^{50}$ SAINT GIRONS, 2009, p.19.

${ }^{51}$ NEWMAN, 1992, p. 172.

${ }^{52}$ DANTO, 2015, p. 172.

${ }^{53}$ DANTO, 2015, p. 169.

${ }^{54}$ NEWMAN, 1992, p. 172. 